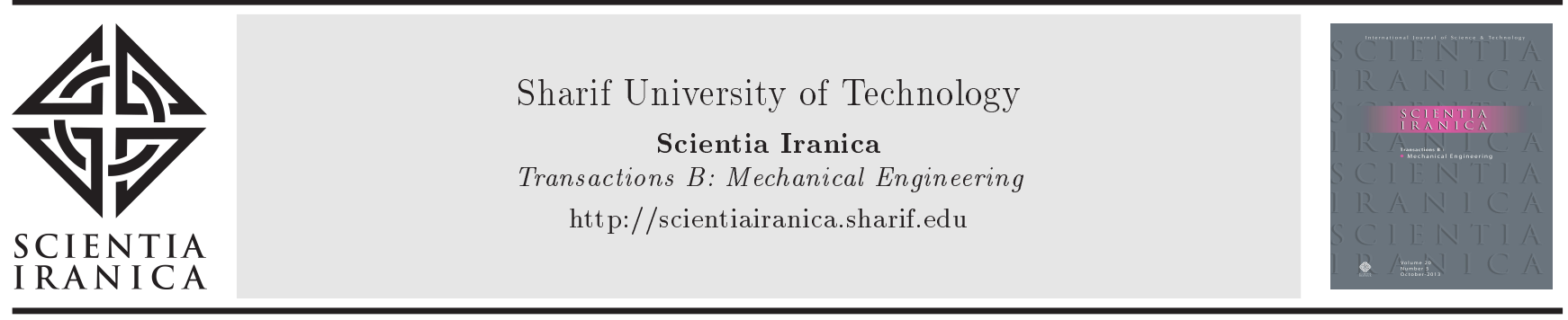

\title{
Influence of areca nut nanofiller on mechanical and tribological properties of coir fibre reinforced epoxy based polymer composite
}

\author{
M. Vishwas ${ }^{\mathrm{a}}$, M. Vinyas ${ }^{\mathrm{b}, *}$, and K. Puneeth ${ }^{\mathrm{c}}$ \\ a. Department of Industrial Engineering and Management, Siddaganga Institute of Technology, Tumakuru-572102, India. \\ b. Department of Mechanical Engineering, Nitte Meenakshi Institute of Technology, Bengaluru, Yelahanka-560064, India. \\ c. Department of Mechanical Engineering, Sri Siddhartha Institute of Technology, Tumakuru, 572105, India.
}

Received 24 October 2018; received in revised form 11 November 2018; accepted 4 February 2019

KEYWORDS
Areca nut;
Coir;
Wear;
Nanofiller;
Polymer matrix
composite;
Mechanical and
tribological properties.

\section{Introduction}

Composites based on natural fibres are finding applications in almost all fields of engineering, since natural fibres have better potential to be a reinforcing material for polymer matrix composites [1]. The varieties of natural fibres like jute, coir, hemp, sisal, banana, and bamboo have established their potential as substitutes for synthetic fibres in many engineering applications owing to their advantages over the synthetic fibres [2-

\footnotetext{
*. Corresponding author.

E-mail address: vinyas.m@nmit.ac.in (M. Vinyas)
}

\begin{abstract}
bstract. The present study was aimed at investigating the effect of incorporating areca composite. Areca nut nanofiller was produced by grinding followed by ball milling. Particle or their mechanical and tribological behaviours using pin on disc rig. Tensile, flexural, and impact tests were carried out on the proposed composite. Taguchi's to analyse the effects of various factors on the tribological behaviour the composite. The results showed that inclusion of areca nut nanofiller enhanced the hardness of the composite. Moreover, it first increased the tensile strength by up , was a decrease in tensile strength. Flexural strength significantly increased with increase in filler percentage from $0 \%$ to $5 \%$, but the variation of flexural
\end{abstract} (C) 2020 Sharif University of Technology. All rights reserved.
7]. Coir is the most commonly used natural fibre obtained from coconut fruit and it is abundantly available in Southern parts of India. This fibre has multiple features such as low weight and cost and high specific strength [8-11], which make it a potential candidate for substituting synthetic fibres. Many researchers suggested using coir fibres as a suitable reinforcement in composites due to its excellent mechanical properties. The coconut shell based nanofiller was used in hybrid kenaf/coir reinforced vinyl ester composite and it was reported that incorporation of the filler enhanced the mechanical properties of the composite [12].

Studies carried out by various researchers confirm that the wear resistance of polymer is enhanced when it is reinforced with fibres [13] or used with 
lubricants $[14,15]$. In addition, some other studies have shown that the incorporation of nano particles enhances the tribological properties of polymers [1620]. To achieve better wear properties, many researchers have modified the polymers using different fillers [21-24]. Addition of $\mathrm{CuO}$ and $\mathrm{Pb}_{3} \mathrm{O}_{4}$ as fillers enhanced the wear resistance of high-density polyethylene (HDPE) [21]. $\mathrm{ZrO}_{2}$ and $\mathrm{TiO}_{2}$ as fillers reduced the loss of mass due to wear in polytetrofluroethylene (PTFE) [22]. Compounds of copper, like $\mathrm{CuO}$ and $\mathrm{CuS}$, resulted in enhanced wear resistance of polyether ether ketone (PEEK), PTFE, nylon, and HDPE [24]. Most of the studies of fillers cited above deal with metallic fillers. The effect of natural plant based fillers on the tribological behaviour of polymer matrix composites has less been explored. Controlling the length of abaca fibre, the wear resistance of the friction composite can be significantly enhanced [25].

Natural areca nut (areca catechu) is inexpensive and abundantly available. Karnataka is largest areca nut producing state in India, which has a share of around $50 \%$ of the whole areca production in the country. Chemically treated areca fibre reinforced epoxy composite provides better impact properties [26] Physio-mechanical properties of hybrid betel nut (areca catechu) short fibre/seaweed polypropylene composite has been studied previously. It was reported that with increase in filler percentage, the tensile strength decreased [27].

Although abundant research on the tribological behaviour of composites has been carried out, the use of natural plant based fillers in polymer matrix composite has less been addressed. Few researchers have reported the use of areca nut as a fibre in the composite, but its use as a filler in composites for tribological applications is not reported. In this regard, the present work is focused on exploring the use of plant based areca nut (areca catechu) as filler in polymer matrix and its effect on the tribological properties of the composite.

\section{Taguchi's Design of Experiments (DoE)}

Taguchi's Design of Experiments (DoE) statistical technique is a very useful and powerful tool for designing the experiments. It involves a systematic way of collecting data, analysing them, and interpreting the results $[28,29]$. The advantage of using Taguchi technique is that more amount of information can be obtained with minimum experimentation and hence, the time and cost are reduced. The performance characteristics can be optimized through this method. However, the selection of factors is the critical stage in this methodology. Taguchi method makes use of orthogonal array to incorporate various factors and defines the plan of experiments. The responses obtained are analysed through mean, Signal to Noise (SN) ratio, and Analysis of Variance (ANOVA) to which the regression model can be fitted.

\section{Materials and methods}

\subsection{Composite preparation}

The proposed composite makes use of areca nut nanofiller in the epoxy matrix, which is reinforced by coir fibre. L12 epoxy with K6 hardener is used for its better resistance to alkali and good adhesive property. The coir fibres in the form of woven mat and the areca nut were procured from the local suppliers of Tumakuru district, Karnataka, India. Areca nut nanofiller is produced by grinding followed by ball milling. Particle size analyser confirmed that the size of nanofillers obtained was in the range of 20-100 nm. The composition and weight fraction of the composite with varied fillers, fibres, and matrices are shown in Table 1.

The composites were fabricated adopting hand layup technique and cured at room temperature for 24 hours. The specimen conforming to ASTM G99-95 standard was cut from the cured laminate.

\subsection{Test of density, micro hardness, tensile, flexural, and impact properties}

\subsubsection{Density}

Theoretical density can be found by using Eq. (1) according to [30]:

$$
\rho_{t h}=\frac{1}{\left(\frac{W_{f}}{\rho_{f}}+\frac{W_{m}}{\rho_{m}}\right)},
$$

where $W$ is the weight fraction and $\rho$ is the density. The suffixes $m, f$, and $t h$ stand for matrix, fibre, and theoretical, respectively. Since the present study makes use of filler, Eq. (1) can be modified by Eq. (2):

$$
\rho_{t h}=\frac{1}{\left(\frac{W_{f}}{\rho_{f}}+\frac{W_{m}}{\rho_{m}}+\frac{W_{p}}{\rho_{p}}\right)} .
$$

The void percentage is determined using Eq. (3):

$$
\text { Void content }(\%)=\left(\frac{\rho_{t h}-\rho_{a}}{\rho_{t h}}\right) \times 100 \text {, }
$$

where $\rho_{t h}$ is theoretical density and $\rho_{a}$ is actual density calculated using Archimedes principle.

Table 1. Composition and weight fraction of the composites with varied fillers, fibres, and matrices.

\begin{tabular}{cccc}
\hline \multirow{2}{*}{$\begin{array}{c}\text { Composite } \\
\text { designation }\end{array}$} & \multicolumn{3}{c}{ Weight percentage } \\
\cline { 2 - 4 } & $\begin{array}{c}\text { Arecanut } \\
\text { powder }\end{array}$ & Coir & Epoxy \\
\hline C1 & 0 & 40 & 60 \\
C2 & 5 & 40 & 55 \\
C3 & 10 & 40 & 50 \\
\hline
\end{tabular}




\subsubsection{Micro hardness}

Micro hardness testing machine was used to calculate the Vickers harness number of the composite. In the present study, the load of $29.43 N$ was applied to the specimen. Vickers hardness number is calculated using Eqs. (4) and (5):

$$
\begin{aligned}
& H_{v}=0.1889 \times \frac{F}{L^{2}}, \\
& L=\frac{X+Y}{2},
\end{aligned}
$$

where $F$ is the applied Newtonian load, $L$ is the diagonal of square impression in millimeters, $X$ is the horizontal length in millimeters, and $Y$ is the vertical length in millimeters.

\subsubsection{Tensile strength}

The tensile test was carried out by applying a uniaxial load according to ASTM D3039-76. The crosshead speed of the universal testing machine was maintained at $10 \mathrm{~mm} / \mathrm{min}$ and the results were analysed to find the tensile strength of the composites. Five specimens of each composite configuration were tested and the averages were considered.

\subsubsection{Inter-laminar shear and flexural strength}

To find the inter-laminar shear strength, short beam shear tests were performed according to ASTM D234484 standard and the flexural strength and inter-laminar shear strength were calculated using Eqs. (6) and (7), respectively. The dimensions of the specimen used were $60 \mathrm{~mm} \times 10 \mathrm{~mm} \times 4 \mathrm{~mm}$. The crosshead speed and span length were maintained at $10 \mathrm{~mm} / \mathrm{min}$ and $40 \mathrm{~mm}$, respectively. Five samples of each composite configuration were tested separately for flexural and shear tests:

$$
\begin{aligned}
& F_{s}=\frac{3 P L}{2 b t^{2}}, \\
& I_{s}=\frac{3 P}{4 b t},
\end{aligned}
$$

where $P$ is the maximum load and $b$ is the width, $t$ the thickness, and $L$ the span length of the specimen.

\subsubsection{Impact test}

Pendulum-based low-velocity impact test was carried out according to ASTM D256 standard with $V$-notch and notch depth of $20 \mathrm{~mm}$. Five specimens of each composite configuration were tested and the average values were considered. The specimens were fixed in a square support and impacted at their central point by a hemispherical bolt of $4 \mathrm{~mm}$ diameter. The respective values of impact energy for different specimens were recorded directly from the dial indicator.

\subsubsection{Experimental design and wear runs}

In order to investigate the dry sliding wear behaviour of the proposed composite, a pin on disc test apparatus was used. The specifications of the disc are given in Table 2.

The parameters considered to be varied were the speed, load, and distance. Before subjecting the composite specimens to testing, they were cleaned with acetone. The initial weight of the specimen was measured using precision weighing balance. During the test, pin was pressed against the counterpart rotating against the steel disc by applying load. After completing the specified sliding distance for the specimen, it was removed, cleaned with acetone, and dried. Then, its final weight was noted down to find the weight loss due to wear. The weight loss of the composite due to wear was calculated using Eq. (8):

$$
\text { Weight loss }=\text { Initial weight }- \text { Final weight. }
$$

Weight fraction of the filler in terms of composite designation, sliding speed, and load and sliding distances was considered variable in the present study. The factors and their levels chosen in the present study are represented in Table 3. Experimentations were conducted according to Taguchi's L9 orthogonal array in order to investigate the effect of the filler and other chosen parameters on the wear resistance of the composites. The plan of experiments is represented in Table 4.

\section{Results and discussions}

\subsection{Mechanical properties}

The theoretical and experimental densities of the composites with varied weight percentages of areca nut nanofiller are given in Table 5. The density of neat resin mixed with hardener with the ratio of 10:1 was found $1040 \mathrm{~kg} / \mathrm{m}^{3}$. As seen in Figure 1, with the addition of

Table 2. Specifications of the disc.

\begin{tabular}{lcccc}
\hline Material & HRC & Diameter & Thickness & $\begin{array}{c}\text { Surface } \\
\text { roughness }\end{array}$ \\
\hline $\begin{array}{l}\text { En-32 steel } \\
\text { Hardened }\end{array}$ & 62 & $135 \mathrm{~mm}$ & $8 \mathrm{~mm}$ & $0.8 \mu \mathrm{m}$ \\
\hline
\end{tabular}

Table 3. Factors and levels used in the Taguchi study.

\begin{tabular}{lccc}
\hline \multicolumn{1}{c}{ Factors } & Level 1 & Level 2 & Level 3 \\
\hline Composite designation & $\mathrm{C} 1$ & $\mathrm{C} 2$ & $\mathrm{C} 3$ \\
Sliding speed (m/s) & 2 & 4 & 6 \\
Load (N) & 10 & 20 & 30 \\
Sliding distance (m) & 500 & 1000 & 1500 \\
\hline
\end{tabular}


the filler, the density of the composite was reduced and the void percentage increased.

Table 6 provides the hardness value, tensile strength, flexural and interlaminar shear strength, and impact strength of the composites, which are also graphically represented in Figure 2.

The wear resistance of a composite mainly depends on its hardness. The microhardness test carried out showed that with the incorporation of areca nut nanofiller from $0 \%$ to $10 \%$, the hardness of the coir reinforced epoxy composite increased from $18 \mathrm{Hv}$ to $27 \mathrm{Hv}$, as presented in Table 6. Figure 2 shows the variation of hardness value of composite with varying filler percentage. It can be seen that with the addition of filler, the hardness values significantly increases. The variation of tensile strength of the coir-reinforced epoxy composite is presented in Table 6. From Figure 2, it can be concluded that with the inclusion of areca nut filler, tensile strength increases by up to $5 \%$ and after that, it experiences a decrease.

The flexural and inter-laminar shear strength

Table 4. Plan of experiments according to Taguchi's L9 orthogonal array.

\begin{tabular}{cccc}
\hline $\begin{array}{c}\text { Composite } \\
\text { designation }\end{array}$ & $\begin{array}{c}\text { Sliding } \\
\text { speed }\end{array}$ & Load & $\begin{array}{c}\text { Sliding } \\
\text { distance }\end{array}$ \\
\hline 1 & 1 & 1 & 1 \\
1 & 2 & 2 & 2 \\
1 & 3 & 3 & 3 \\
2 & 1 & 2 & 3 \\
2 & 2 & 3 & 1 \\
2 & 3 & 1 & 2 \\
3 & 1 & 3 & 2 \\
3 & 2 & 1 & 3 \\
3 & 3 & 2 & 1 \\
\hline
\end{tabular}

of the coir reinforced composite with various filler loading percentages is presented in Table 6 . The variation of flexural strength and inter-laminar shear strength of the composite with different percentages of

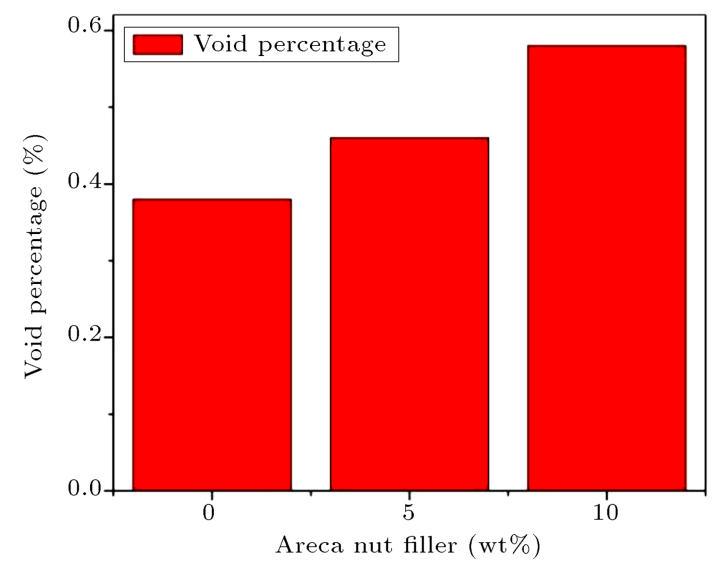

Figure 1. Variation of void percentage with inclusion of filler.

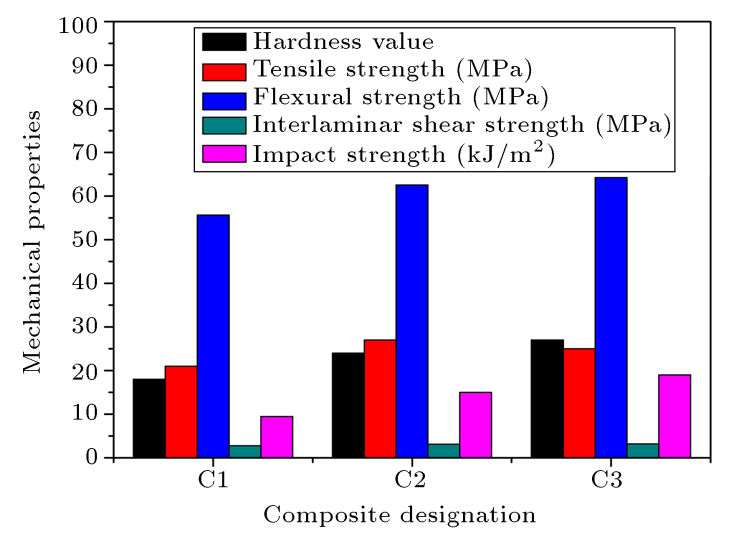

Figure 2. Variation of mechanical properties with inclusion of filler percentage.

Table 5. Theoretical and experimental densities of composites.

\begin{tabular}{ccccc}
\hline $\begin{array}{c}\text { Composite } \\
\text { designation }\end{array}$ & $\begin{array}{c}\text { Weight } \\
\text { percentage } \\
\text { of filler }\end{array}$ & $\begin{array}{c}\text { Theoretical } \\
\text { density } \\
\left(\mathbf{k g} / \mathbf{m}^{\mathbf{3}}\right)\end{array}$ & $\begin{array}{c}\text { Actual } \\
\text { density } \\
\left(\mathbf{k g} / \mathbf{m}^{\mathbf{3}}\right)\end{array}$ & $\begin{array}{c}\text { Void } \\
\text { percentage }\end{array}$ \\
\hline C1 & 0 & 1023.62 & 1019.73 & 0.38 \\
C2 & 5 & 1004.50 & 999.87 & 0.46 \\
C3 & 10 & 986.09 & 980.37 & 0.58 \\
\hline
\end{tabular}

Table 6. Properties of composites for various percentages of filler.

\begin{tabular}{cccccccc}
\hline $\begin{array}{c}\text { Composite } \\
\text { designation }\end{array}$ & $\begin{array}{c}\text { Filler } \\
\text { percentage }\end{array}$ & $\begin{array}{c}\text { Hardness } \\
\text { value }\end{array}$ & $\begin{array}{c}\text { Tensile } \\
\text { strength } \\
(\mathbf{M P a})\end{array}$ & $\begin{array}{c}\text { Maximum } \\
\text { load } \\
(\mathbf{N})\end{array}$ & $\begin{array}{c}\text { Flexural } \\
\text { strength } \\
(\mathbf{M P a})\end{array}$ & $\begin{array}{c}\text { Inter-laminar } \\
\text { shear } \\
\text { strength } \\
(\mathbf{M P a})\end{array}$ & $\begin{array}{c}\text { Impact } \\
\text { strength } \\
\left(\mathbf{k J} / \mathbf{m}^{\mathbf{2}}\right)\end{array}$ \\
\hline C1 & 0 & 18 & 21 & 148.34 & 55.63 & 2.78 & 9.5 \\
C2 & 5 & 24 & 27 & 166.77 & 62.54 & 3.12 & 15 \\
C3 & 10 & 27 & 25 & 171.28 & 64.23 & 3.21 & 19 \\
\hline
\end{tabular}


incorporated filler is also given in Figure 2. It can be observed that flexural strength significantly increases with increase in filler percentage from $0 \%$ to $5 \%$, but its variation from $5 \%$ to $10 \%$ is negligible. Similarly, it can be observed that the inclusion of filler has negligible effect on the inter-laminar shear strength of composites.

The impact energy absorbed by the coir reinforced composite with various filler loading percentages is presented in Table 6. In Figure 2, it is evident that the impact strength of the composite is enhanced with the incorporation of the filler and with the addition of more amounts of filler, impact strength increases.

\section{2. $S N$ ratio}

Table 7 gives the weight loss as a response to different combinations of factors along with SN ratios and means obtained for various runs of Taguchi's L9 orthogonal array.

The aim was to minimize the weight loss of the composite due to wear. Hence, the SN ratio was calculated to achieve the minimum weight loss with "the smaller the better" criterion as a logarithmic transformation of the loss function given by Eq. (9):

$$
S / N=-10 \log _{10}\left(\left(\Sigma y^{2}\right) / n\right),
$$

where $y$ is the response for a given factor level combination and $n$ is the number of responses in the factor level combination.

The present study makes use of the commercially available statistical tool of MINITAB 17 for the computational practices. The 'weight loss' response of the composite was analysed and the effect of the factors on the response was studied. The responses for $\mathrm{SN}$ ratios are given in Table 8. Analysing the weight loss of the composites showed that composite designation at level 3 (10\% weight fraction of areca nut nanofiller) with the highest $\mathrm{SN}$ ratio gave minimum wear loss. Moreover, it can be stated that the wear loss of the composite mainly depended on the filler percentage (composite designation) followed by load, sliding distance, and sliding speed. Thus, inclusion of the areca nut nanofiller enhanced the wear resistance of the composite.

Figure 3 shows the plots for the main effects of means and SN ratios. It is observable that the minimum wear loss was obtained when the filler percentage in the composite was high (level 3). According to the interaction plot for weight loss in Figure 4, since there are no parallel lines, there exists an interaction among all the factors considered for the weight loss of the composite, with filler percentage (composite designation) being the most significant factor.

\subsection{ANOVA}

ANOVA is a proper statistical means for finding the significant factors. It indicates to what extent a process parameter influences the response calculates its significance level. The ANOVA values for the weight loss of the composites are presented in Table 9 .

According to the table, among the control fac-

Table 7. Signal to Noise (SN) ratios and means for various runs.

\begin{tabular}{cccccccc}
\hline Runs & $\begin{array}{c}\text { Composite } \\
\text { designation }\end{array}$ & $\begin{array}{c}\text { Sliding } \\
\text { speed }\end{array}$ & Load & $\begin{array}{c}\text { Sliding } \\
\text { distance }\end{array}$ & $\begin{array}{c}\text { Weight } \\
\text { loss }(\mathbf{g m s})\end{array}$ & $\begin{array}{c}\text { SN ratio } \\
(\mathbf{d B})\end{array}$ & Mean \\
\hline 1 & 1 & 1 & 1 & 1 & 0.28 & 11.0568 & 0.28 \\
2 & 1 & 2 & 2 & 2 & 0.32 & 9.8970 & 0.32 \\
3 & 1 & 3 & 3 & 3 & 0.35 & 9.1186 & 0.35 \\
4 & 2 & 1 & 2 & 3 & 0.24 & 12.3958 & 0.24 \\
5 & 2 & 2 & 3 & 1 & 0.20 & 13.9794 & 0.20 \\
6 & 2 & 3 & 1 & 2 & 0.22 & 13.1515 & 0.22 \\
7 & 3 & 1 & 3 & 2 & 0.20 & 13.9794 & 0.20 \\
8 & 3 & 2 & 1 & 3 & 0.16 & 15.9176 & 0.16 \\
9 & 3 & 3 & 2 & 1 & 0.18 & 14.8945 & 0.18 \\
\hline
\end{tabular}

Table 8. Response table of Signal to Noise (SN) ratios for all three stacking sequences.

\begin{tabular}{ccccc}
\hline Levels & $\begin{array}{c}\text { Composite } \\
\text { designation }\end{array}$ & $\begin{array}{c}\text { Sliding } \\
\text { speed } \mathbf{( m / s )}\end{array}$ & Load $(\mathbf{N})$ & $\begin{array}{c}\text { Sliding } \\
\text { distance }(\mathbf{m})\end{array}$ \\
\hline 1 & 10.02 & 12.48 & 13.38 & 13.31 \\
2 & 13.18 & 13.26 & 12.40 & 12.34 \\
3 & $\mathbf{1 4 . 9 3}$ & 12.39 & 12.36 & 12.48 \\
Delta & 4.91 & 0.88 & 1.02 & 0.97 \\
Rank & 1 & 4 & 2 & 3 \\
\hline
\end{tabular}




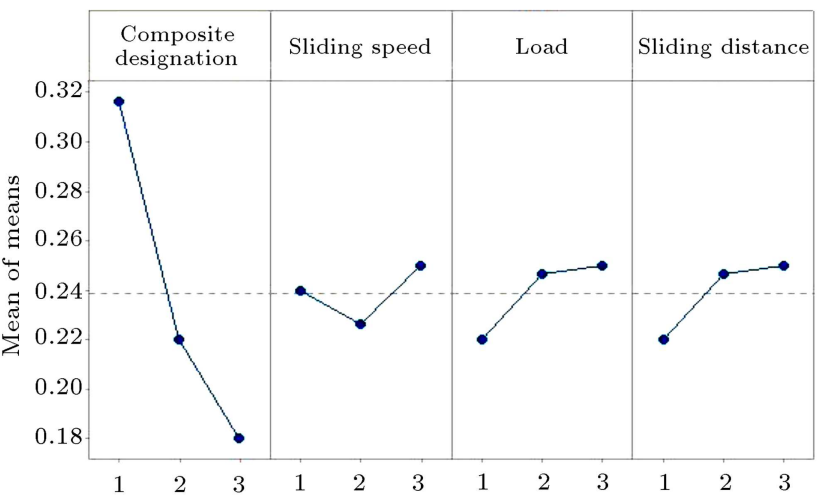

(a)

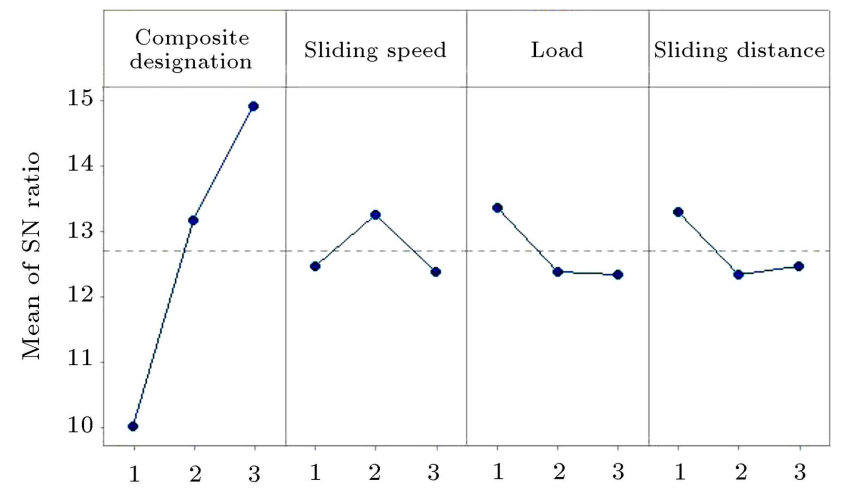

(b)

Signal-to-noise: Smaller is better

Figure 3. Main effect plot for (a) means and (b) Signal to Noise (SN) ratios.

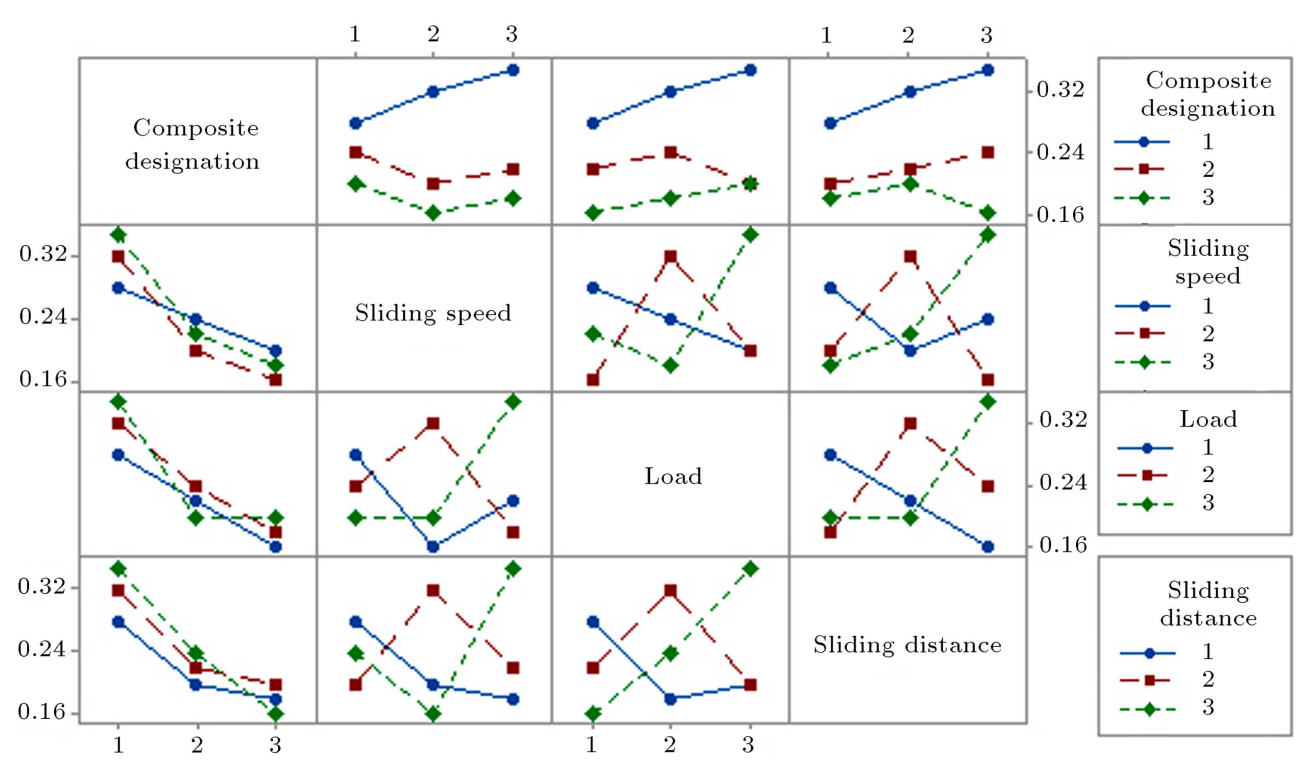

Figure 4. Interaction effect plot for weight loss of composites.

tors, composite designation (filler percentage) has the highest $F$ value, followed by load/sliding distance and sliding speed. In addition, the percentage contribution, calculated using Eq. (10), is the highest for composite designation (filler percentage), which indicates that filler percentage has a significant effect on the weight loss of the composite due to erosion. The $R$-sq value indicates the coefficient of determination for an

Table 9. Analysis of variance (ANOVA) for weight loss of composites.

\begin{tabular}{lcccccc}
\hline \multicolumn{1}{c}{ Source } & DF & SS & MS & $\boldsymbol{F}$ value & $\boldsymbol{P}$ value & Contribution $(\%)$ \\
\hline Composite designation & 1 & 0.028017 & 0.028017 & 39.71 & 0.003 & 83.16 \\
Sliding speed & 1 & 0.000150 & 0.000150 & 0.21 & 0.669 & 0.44 \\
Load & 1 & 0.001350 & 0.001350 & 1.91 & 0.239 & 4 \\
Sliding distance & 1 & 0.001350 & 0.001350 & 1.91 & 0.239 & 4 \\
Error & 4 & 0.002822 & 0.000706 & & & 8.37 \\
Total & 8 & 0.033689 & & & \\
& \\
$S=0.0265623$, R-sq $=91.67 \%$, R-sq (adj) $=90.25 \%$ & & \\
\end{tabular}


equation. It is more than $90 \%$ in this study, which indicates that the developed model gives good results and helps to predict the weight loss values within experimental conditions.

$$
\% \text { contribution }=\left(\frac{S S_{f}}{S S_{t}}\right) * 100
$$

where $S S_{f}$ is the sum of squares of a factor and $S S_{t}$ is the total sum of squares.

\subsection{Regression analysis}

Regression models are developed for the output responses and the regression equation developed for the composite is shown in Eq. (11):

Weight loss $=0.3056-0.0683$ Composite designation

$$
\begin{aligned}
& +0.0050 \text { Sliding speed }+0.0150 \text { Load } \\
& +0.0150 \text { Sliding distance. }
\end{aligned}
$$

The coefficient associated with the control factors indicates that increase in filler percentage leads to a reduction in weight loss. Furthermore, filler percentage has the highest coefficient, indicating that the influence of filler on weight loss is significant compared to other factors.

In order to validate the developed model, the experimental results are compared with the predicted results in Table 10. he error percentage was found within $10 \%$, indicating that the developed models were adequate and feasible to predict the weight loss due to wear within the range of experimental conditions. Figure 5 shows the comparison of experimental and calculated values of weight loss.

\subsection{Contour plots}

Figure 6 shows the contour plots for weight loss against various combinations of factors. It can be seen from all the graphs that the weight loss is maximum at the first level of composite designation ( $0 \%$ filler) and the third

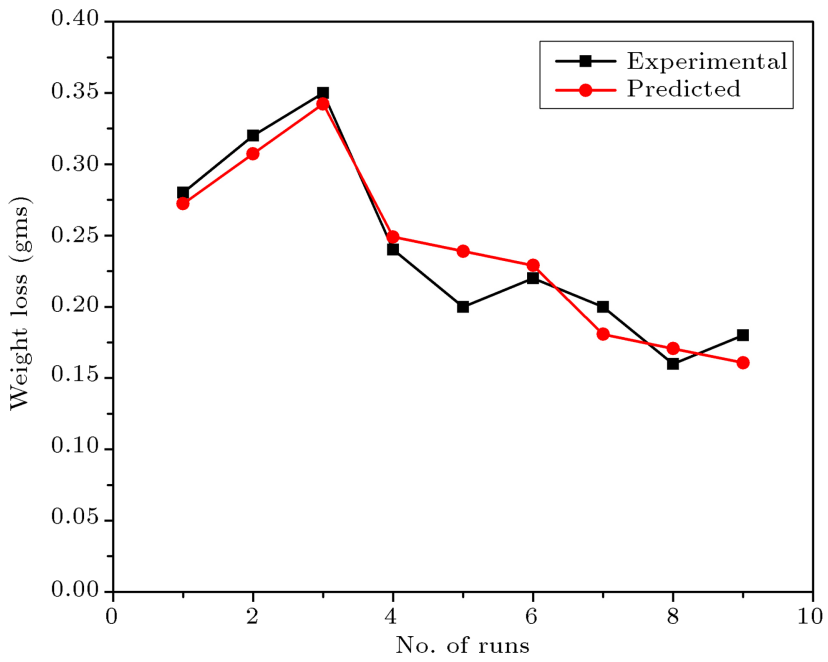

Figure 5. Comparison of experimental and predicted values of weight loss for composites.

level of load $(30 \mathrm{~N})$ with sliding distance of $1500 \mathrm{~m}$ and sliding speed of $6 \mathrm{~m} / \mathrm{s}$. On the other hand, minimum weight loss is obtained at the third level of composite designation ( $10 \%$ filler), which means that weight loss is minimized with increase in filler percentage.

\section{Conclusions}

In the present study, the effects of various percentages of areca nut nanofiller on the wear behaviour of the coir reinforced epoxy based polymer matrix composite were studied. The impacts of various factors on the mechanical and tribological properties of the composite were investigated. It was found that with the addition of the filler, the density of the composite was reduced and the void percentage and microhardness increased. The tensile strength of the composite was enhanced by the inclusion of the filler by up to $5 \%$ and after that, it decreased. Flexural strength significantly increased with increase in filler percentage from $0 \%$ to $5 \%$, but its variation was negligible from $5 \%$ to

Table 10. Comparison of the experimental and calculated values of weight loss for composites.

\begin{tabular}{ccccccc}
\hline $\begin{array}{c}\text { Composite } \\
\text { designation }\end{array}$ & $\begin{array}{c}\text { Sliding } \\
\text { speed }\end{array}$ & Load & $\begin{array}{c}\text { Sliding } \\
\text { distance }\end{array}$ & $\begin{array}{c}\text { Experimental } \\
\text { weight } \\
\text { loss (gms) }\end{array}$ & $\begin{array}{c}\text { Predicted } \\
\text { weight } \\
\text { loss (gms) }\end{array}$ & $\begin{array}{c}\text { Percentage } \\
\text { error }\end{array}$ \\
\hline 1 & 1 & 1 & 1 & 0.28 & 0.2723 & 2.75 \\
1 & 2 & 2 & 2 & 0.32 & 0.3073 & 3.96 \\
1 & 3 & 3 & 3 & 0.35 & 0.3423 & 2.20 \\
2 & 1 & 2 & 3 & 0.24 & 0.249 & -3.75 \\
2 & 2 & 3 & 1 & 0.20 & 0.239 & -19.50 \\
2 & 3 & 1 & 2 & 0.22 & 0.229 & -4.09 \\
3 & 1 & 3 & 2 & 0.20 & 0.1807 & 9.65 \\
3 & 2 & 1 & 3 & 0.16 & 0.1707 & -6.68 \\
3 & 3 & 2 & 1 & 0.18 & 0.1607 & 10.72 \\
\hline
\end{tabular}




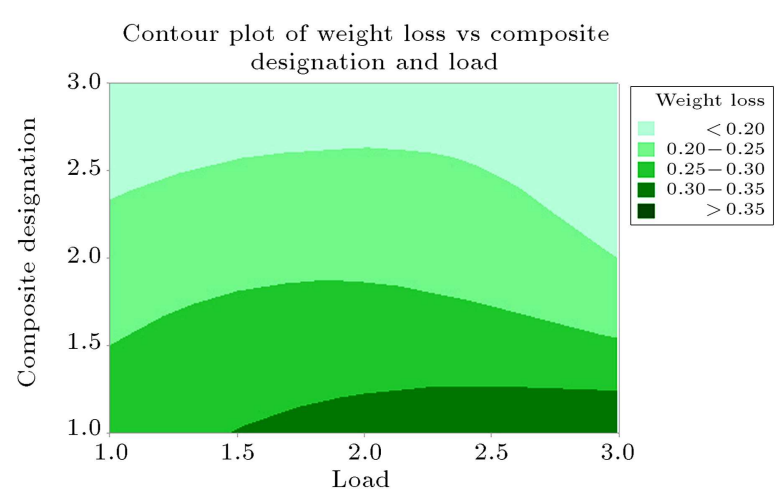

(a)

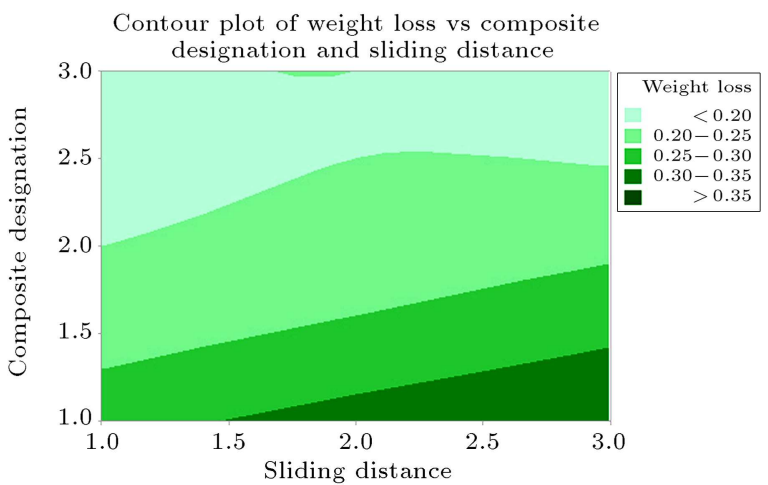

(b)

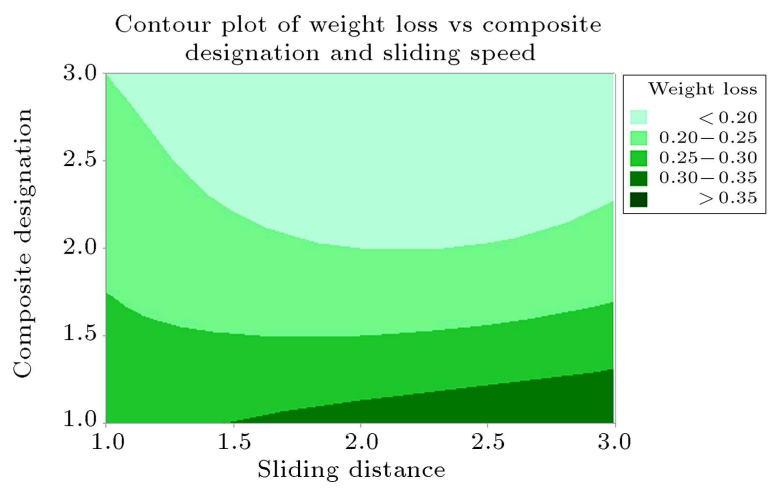

(c)

Figure 6. Contour plots of weight loss against various combinations of factors.

$10 \%$. It was observed that the inclusion of filler had negligible effect on the inter-laminar shear strength of the composites. Impact strength of the composite was enhanced with the incorporation of the filler. It was concluded that the incorporation of areca nut nanofiller significantly enhanced the wear resistance of the composite. Incorporating $10 \%$ weight fraction of areca nut nanofiller gave lower wear loss than $5 \%$ and no incorporation. It was found that the wear loss of the composite mainly depended on the filler percentage followed by load, sliding distance, and sliding speed. Analysis of variance (ANOVA) showed that the percentage contribution of filler loading was the highest $(83.16 \%)$, followed by load/sliding distance $(4 \%)$ and sliding speed $(0.44 \%)$. Moreover, regression model was developed and validated. It was observed that the error percentage was within $10 \%$, indicating that the developed models were adequate and feasible to predict the weight loss due to wear within the range of experimental conditions.

\section{References}

1. Shuhimi, F.F, Abdollah, M.F. Bin, Kalam, M.A., et al. "Tribological characteristics comparison for oil palm fibre/epoxy and kenaf fibre/epoxy composites under dry sliding conditions", Tribol. Int., 101, pp. 247-254 (2016).
2. Alves, C., Ferrão, P.M.C., Silva, A.J., et al. "Ecodesign of automotive components making use of natural jute fiber composites", J. Clean Prod., 18, pp. 313-327 (2010).

3. Faruk, O., Bledzki, A.K., Fink, H.P., et al. "Biocomposites reinforced with natural fibers: 2000-2010", Prog. Polym. Sci., 37, pp. 1552-1596 (2012).

4. Thomas, S., Paul, S.A., and Pothan, B.D., Natural Fibres: Structure, Properties and Applications. In: Susheel Kalia, B.S. Kaith IK, Ed. Cellul. Fibers BioNano-Polymer Compos., Springer, Berlin, Heidelberg, pp. 3-42 (2011).

5. Pickering, K.L., Beckermann, G.W., Alam, S.N., et al. "Optimising industrial hemp fibre for composites", Compos. Part A Appl. Sci. Manuf., 38, pp. 461-468 (2007).

6. Joshi, S.V., Drzal, L.T., Mohanty, A.K., et al. "Are natural fiber composites environmentally superior to glass fiber reinforced composites?", Compos. Part A Appl. Sci. Manuf., 35, pp. 371-376 (2004).

7. Davoodi, M.M., Sapuan, S.M., Ahmad, D., et al. "Concept selection of car bumper beam with developed hybrid bio-composite material", Mater. Des., 32, pp. 4857-4865 (2011).

8. Ghavami, K., Toledo Filho, R.D., and Barbosa, N.P. "Behaviour of composite soil reinforced with natural fibres", Cem. Concr. Compos., 21, pp. 39-48 (1999). 
9. Herrera-Franco, P.J. and Valadez-González, A. "Mechanical properties of continuous natural fibrereinforced polymer composites", Compos. Part A Appl. Sci. Manuf., 35, pp. 339-345 (2004).

10. Brahmakumar, M., Pavithran, C., and Pillai, R.M. "Coconut fibre reinforced polyethylene composites: Effect of natural waxy surface layer of the fibre on fibre/matrix interfacial bonding and strength of composites", Compos. Sci. Technol., 65, pp. 563-569 (2005).

11. Rout, J., Misra, M., Tripathy, S.S., et al. "The influence of fibre treatment of the performance of coirpolyester composites", Compos. Sci. Technol., 61, pp. 1303-1310 (2001).

12. Khalil AHPS, Masri M., Saurabh, C.K., et al. "Incorporation of coconut shell based nanoparticles in kenaf/coconut fibres reinforced vinyl ester composites", Mater. Res. Express, 4, p. 035020 (2017).

13. Basavarajappa, S., Arun, K.V., and Davim, J.P. "Effect of filler materials on dry sliding wear behavior of polymer matrix composites-A taguchi approach", Mater. Charact., 8, pp. 379-391 (2009).

14. Syahrullail, S., Izhan, M.I., and Rafiq, A.K.M. "Tribological investigation of RBD palm olein in different sliding speeds using pin-on-disk tribotester", Sci. Iran. Trans. Mech. Eng., 21, pp. 162-170 (2014).

15. Farhanah, A., Syahrullail, S. and Bahru, J. "Tribological behavior of refined, bleached and deodorized palm kernel as an alternative lubricant", Sci. Iran. Trans. Mech. Eng., 25, pp. 1169-1178 (2018).

16. Österle, W., Dmitriev, A.I, Wetzel, B., et al. "The role of carbon fibers and silica nanoparticles on friction and wear reduction of an advanced polymer matrix composite", Mater. Des., 93, pp. 474-484 (2016).

17. Rostamiyan, Y., Fereidoon, A., Rezaeiashtiyani, M., et al. "Experimental and optimizing flexural strength of epoxy-based nanocomposite: Effect of using nano silica and nano clay by using response surface design methodology", Mater. Des., 69, pp. 96-104 (2015).

18. Dmitriev, A.I., Häusler, I., Österle, W., et al. "Modeling of the stress-strain behavior of an epoxy-based nanocomposite filled with silica nanoparticles", Mater. Des., 89, pp. 950-956 (2016).

19. Sebastian, S., Lothar, K., and Schettler F. "Nanoparticle reinforced epoxy gelcoats for fiber-plastic composites under multiple load", Process. Org. Coatings, 77, pp. 1129-1136 (2014).

20. Suresha, B., Chandramohan, G., Prakash, J.N., et al. "The role of fillers on friction and slide wear characteristics in glass-epoxy composite systems", $J$. Miner Mater. Charact. Eng., 5, pp. 87-101 (2006).

21. Briscoe, B.J., Pogosian, A.K., and Tabor, D. "The friction and wear of high density polythene: The action of lead oxide and copper oxide fillers", Wear, 27, pp. 19-34 (1974).
22. Tanaka, K. and Kawakami, S. "Effect of various fillers on the friction and wear of polytetrafluoroethylenebased composites", Wear, 79, pp. 221-234 (1982).

23. Bahadur, S. and Tabor, D. "Role of fillers in the friction and wear behavior of high-density polyethylene.", Polym. Wear Its Control, 287, pp. 253-268 (1985).

24. Kishore, Sampathkumaran, P., Seetharamu, S., et al. "SEM observations of the effects of velocity and load on the sliding wear characteristics of glass fabric-epoxy composites with different fillers", Wear, 237, pp. 2027 (2000).

25. Liu, Y., Ma, Y., Che, J., et al. "Natural fibre reinforced non-asbestos organic non-metallic friction composites: Effect of abaca fibre on mechanical and tribological behaviour", Mater. Res. Express, 5, p. 055101 (2018).

26. Dhanalakshmi, S., Ramadevi, P., and Basavaraju, B. "Areca fiber reinforced epoxy composites: Effect of chemical treatments on impact strength", Oriental Journal of Chemistry, 4, pp. 409-418 (2015).

27. Hassan, M.M., Wagner, M.H., Zaman, H.U., et al. "Physico-mechanical performance of hybrid betel nut (areca catechu) short fiber/seaweed polypropylene composite", J. Nat. Fibers, 7, pp. 165-177 (2010).

28. Ross, P.J., Taguchi Techniques for Quality Engineering, New Delhi: Tata McGraw Hill Publishing Company Limited (2008).

29. Basavarajappa, S., Chandramohan, G., Mahadevan, A., et al. "Influence of sliding speed on the dry sliding wear behaviour and the subsurface deformation on hybrid metal matrix composite", Wear, 262, pp. 10071012 (2007).

30. Agarwal, B.D., Analysis and Performance of Fiber Composites., 2nd Ed., John Wiley and Sons, Inc (1990).

\section{Biographies}

Mahesh Vishwas received his Bachelor of Engineering in Mechanical Engineering and Master of Technology in Product Design and Manufacturing in 2007 and 2011, respectively, from Visvesvaraya Technological University, Belagavi, Karnataka, India. He is now working as an Assistant Professor in the Department of Industrial Engineering and Management of Siddaganga Institute of Technology, Tumakuru, Karnataka, India. His research interests include composite materials. He has published and presented many papers in international journals and conferences.

Mahesh Vinyas received his BSc in Mechanical Engineering and MSc in Machine Design in 2013 and 2015, respectively, from Visvesvaraya Technological University, Belagavi, Karnataka, India. He was a rank holder of the university during MSc studies. He also completed his $\mathrm{PhD}$ at National Institute of Technology Karnataka, Surathkal, Mangaluru, India 
in 2018. He is currently working as an Assistant Professor in the Department of Mechanical Engineering of Nitte Meenakshi Institute of Technology, Bengaluru, Karnataka, India. He has published and presented papers in more than 25 reputed internal journals and conferences. His research interests include composite materials, computational mechanics, and finite element modelling.

Keshavamurthy Puneeth received his Bachelor of
Engineering in Mechanical Engineering and Master of Technology in Product Design and Manufacturing in 2009 and 2011, respectively, from Visvesvaraya Technological University, Belagavi, Karnataka, India. He is now working as an Assistant Professor in the Department of Mechanical Engineering of Sri Siddhartha Institute of Techology, Tumakuru, Karnataka, India. His research interests include composite materials. He has published and presented many papers in international journals and conferences. 